\title{
Absolute and relative family affluence and psychosomatic symptoms in adolescents
}

Elgar, Frank; De Clercq, Bart; Schnohr, Christina Warrer; Bird, Philippa ; Pickett, Kate E.; Torsheim, Torbjørn; Hofmann, Felix; Currie, Candace

Published in:

Social Science \& Medicine

DOI:

10.1016/j.socscimed.2013.04.030

Publication date:

2013

Document version

Early version, also known as pre-print

Citation for published version (APA):

Elgar, F., De Clercq, B., Schnohr, C. W., Bird, P., Pickett, K. E., Torsheim, T., Hofmann, F., \& Currie, C. (2013).

Absolute and relative family affluence and psychosomatic symptoms in adolescents. Social Science \& Medicine, 91, 25-31. https://doi.org/10.1016/j.socscimed.2013.04.030 


\title{
Absolute and relative family affluence and psychosomatic symptoms in adolescents
}

\author{
Frank J. Elgar ${ }^{\mathrm{a}, \mathrm{b}, *}$, Bart De Clercq $^{\mathrm{c}}$, Christina W. Schnohr ${ }^{\mathrm{d}}$, Phillippa Bird ${ }^{\mathrm{e}}$, Kate E. Pickett ${ }^{\mathrm{e}}$, \\ Torbjørn Torsheim ${ }^{\mathrm{f}}$, Felix Hofmann ${ }^{g}$, Candace Currie ${ }^{\mathrm{h}}$ \\ a Institute for Health and Social Policy, McGill University, 1130 Pine Avenue West, Montreal, Canada \\ ${ }^{\mathrm{b}}$ Douglas Mental Health University Institute, Montreal, Canada \\ ${ }^{\mathrm{c}}$ Department of Public Health, Ghent University, Ghent, Belgium \\ ${ }^{\mathrm{d}}$ Institute of Public Health, University of Copenhagen, Copenhagen, Denmark \\ e Department of Health Sciences, University of York, York, England \\ ${ }^{\mathrm{f}}$ Department of Psychosocial Science, University of Bergen, Bergen, Norway \\ ${ }^{\mathrm{g}}$ Ludwig Boltzmann Institute Health Promotion Research, Vienna, Austria \\ ${ }^{\mathrm{h}}$ School of Medicine, University of St. Andrews, St Andrews, Scotland
}

\section{A R T I C L E I N F O}

\section{Article history:}

Available online 10 May 2013

\section{Keywords:}

Adolecence

Relative deprivation

Yitzhaki index

Health inequalities

Social rank

Psychosomatic symptoms

Health Behaviour in School-aged Children

\begin{abstract}
A B S T R A C T
Previous research on the links between income inequality and health and socioeconomic differences in health suggests that relative differences in affluence impact health and well-being more than absolute affluence. This study explored whether self-reported psychosomatic symptoms in adolescents relate more closely to relative affluence (i.e., relative deprivation or rank affluence within regions or schools) than to absolute affluence. Data on family material assets and psychosomatic symptoms were collected from 48,523 adolescents in eight countries (Austria, Belgium, Canada, Norway, Scotland, Poland, Turkey, and Ukraine) as part of the 2009/10 Health Behaviour in School-aged Children study. Multilevel regression analyses of the data showed that relative deprivation (Yitzhaki Index, calculated in regions and in schools) and rank affluence (in regions) (1) related more closely to symptoms than absolute affluence, and (2) related to symptoms after differences in absolute affluence were held constant. However, differences in family material assets, whether they are measured in absolute or relative terms, account for a significant variation in adolescent psychosomatic symptoms. Conceptual and empirical issues relating to the use of material affluence indices to estimate socioeconomic position are discussed.

(c) 2013 Elsevier Ltd. All rights reserved.
\end{abstract}

\section{Introduction}

The likelihood that young people are happy, healthy and doing well in school is significantly greater as social class rises. Research has found that adolescents at a lower socioeconomic status (SES) display more health compromising behaviours (e.g., physical inactivity, poor nutrition, smoking), report poorer physical health and lower life satisfaction, and exhibit more emotional problems (e.g., depression, anxiety), behavioural problems (e.g., inattentiveness, hyperactivity, aggression) and social skills deficits (Brooks-Gunn, Duncan, \& Maritato, 1997; Chen \& Paterson, 2006; Elgar, Trites, \& Boyce, 2010). Other research has found that income inequality negatively relates to

\footnotetext{
* Corresponding author. Institute for Health and Social Policy, McGill University, 1130 Pine Avenue West, Montreal, Quebec H3A 1A3, Canada. Tel.: +1 514398 1739; fax: +1 5143988983 .

E-mail address: frank.elgar@mcgill.ca (F.J. Elgar).
}

adolescent health, as evidenced in international differences in child wellbeing, teenage pregnancy and school bullying (Elgar, Craig, Boyce, Morgan, \& Vella-Zarb, 2009; Pickett \& Wilkinson, 2007). However, the health consequences of relative deprivation (RD) and rank differences in affluence have not been thoroughly studied in this age group. The focus of this study was to examine absolute and relative differences in family material affluence with regard to their links to psychosomatic symptoms in adolescents.

Adolescence is a formative stage of development for coping resources, mental health and health habits, and SES differences in adolescent health are well documented (Chen, Matthews, \& Boyce, 2002). Some research has found that the health consequences of family affluence wanes during the adolescent years as peer relationships supplant the family as a dominant reference group (West \& Sweeting, 2004) and personal assets (e.g., spending money) become more important than family assets or income (Åberg Yngwe \& Östberg, 2013). Still, SES appears to relate to 
mental and physical health in adolescents regardless of how their status is established, and salient peer influences on status suggests that their health relates not only to absolute affluence but to relative affluence as well.

Research on the mechanisms that underlie SES differences in adult health focuses on the direct consequences of material deprivation and the indirect psychosocial consequences of socioeconomic position (Adler \& Snibbe, 2003; Diener, Sandvik, Seidlitz, \& Diener, 1993; Mackenbach, 2012). According to the materialist hypothesis, SES differences in health arise from unequal distributions of material goods and services and financial resources that can be used to support health or fight and prevent illness. The psychosocial hypothesis posits that feeling poor in comparison to others elicits psychological stress, erodes social resources that help people to cope with stress, and thus contributes to stress-related illness (Marmot \& Wilkinson, 2001; Wilkinson \& Pickett, 2009). These hypotheses are not mutually exclusive, but only the psychosocial interpretation explains why two people with the same income may differ in health when one is surrounded by more affluent people and the other by less affluent people. What differentiates these individuals is not deprivation in absolute terms, such as inadequate nutrition or shelter, but rather feelings of deprivation from a desirable standard of living that is established by society.

These mechanisms have not been thoroughly investigated in adolescents. Although RD is conceptually and computationally related to the Gini coefficient of income inequality, and both RD and social rank are used to interpret contextual effects of income inequality on adolescent health (Wilkinson \& Pickett, 2009), we are unaware of any previous studies that have directly compared absolute affluence, RD and rank affluence in terms of their associations with adolescent health. A recent review of studies of RD and health by Adjaye-Gbewonyo and Kawachi (2012) identified just one study that included data on child health, and it linked maternal RD to birth outcomes (Reagan, Salsberry, \& Randall, 2007). By contrast, nine studies in the review found a significant association between RD and adult health, some after controlling individual differences in absolute income (e.g., Subramanyam, Kawachi, Berkman, \& Subramanian, 2009). Another line of research on income rank and adult wellbeing has found that mental distress (i.e., depressive and anxiety symptoms, social difficulties) and happiness relate more closely to income rank within a reference group than to absolute income (Boyce, Brown, \& Moore, 2010; Wood, Boyce, Moore, \& Brown, 2012).

It is unclear, based on the adult literature, whether relative affluence impacts adolescent health more than absolute affluence. Both are likely to contribute to health inequalities, however the research carried out in modern welfare states appears to favour the psychosocial hypothesis. First, SES differences in mental and physical health are moderated by feelings of autonomy, isolation, stress and social support (Elgar et al., 2010; Marmot, 2004). Having many social connections and low stress helps protect the health of low-SES individuals. Second, the socioeconomic gradient in health exists across the full range of SES, even among relatively affluent groups (Chen \& Paterson, 2006; Marmot, 2004). That the gradient does not disappear above a certain threshold suggests that status matters more to health than the availability of material goods and services. Third, among modern welfare states that have attained the basic material standards to support health of all citizens, the relation between affluence and health is stronger within these countries than between them (Easterlin, 1995; Wilkinson \& Pickett, 2009). Fourth, socioeconomic gradients in health persist after differences in accessing health services and prevalence of health compromising behaviours are held constant (Marmot, 2004). It is difficult to explain these aspects of socioeconomic gradients in health in terms of the direct effects of material conditions alone.
These findings pose unanswered questions about how relative differences in affluence relate to adolescent health. Are adolescents, like adults, similarly affected by absolute and relative affluence? Does RD or affluence rank relate to health after differences in absolute affluence are held constant? The present study addressed these questions using international data on family material assets and psychosomatic symptoms in 11- to 15 -year-olds. The data were collected in eight rich and middle-income countries. We used data on psychosomatic symptom frequency, rather than global assessments of health, to achieve the most objective measure of health possible (Loughnan et al., 2011). Our first objective was to compare three methods of operationalizing socioeconomic conditions with regard to their relation to symptoms: (1) absolute affluence was a summation of family material assets in the home; (2) $R D$ was estimated using the Yitzhaki Index, which is the average difference between an individual's affluence and those with greater affluence in the same reference group (Yitzhaki, 1979); (3) rank affluence was the ordinal position of absolute affluence within a reference group (Boyce et al., 2010; Wood et al., 2012). We hypothesised that RD and rank affluence relate more closely to psychosomatic symptoms than absolute affluence. We also hypothesised, based on similar research on adults, that relative affluence relates to symptoms after differences in absolute affluence are taken into account.

\section{Method}

\section{Participants}

Data on family affluence and psychosomatic symptoms were collected in the 2009/10 Health Behaviours in School-aged Children (HBSC) study. The HBSC study is a school-based survey of nationally representative samples of 11-, 13-, and 15-year-olds in 39 countries in Europe and North America (Currie et al., 2012). Schools that represented the socioeconomic conditions of each participating country were recruited into the study. The HBSC study protocol specifies that samples submitted for international comparisons are sufficient to provide confidence intervals of $\pm 3 \%$ for representative estimates with sample design effects no more than 1.4 times greater than would be obtained from a simple random sample (Currie et al., 2012). Teachers or trained interviewers administered the survey in classroom settings. Student participation was voluntary. Each participating country obtained approval to conduct the survey from the ethics review board or equivalent regulatory body associated with the institution conducting each respective national survey.

We analysed data from eight countries (Table 1): Austria, Belgium (Flanders region), Canada, Norway, Poland, Scotland, Turkey, and Ukraine. Table 1 summarises the number of students, schools and regions per country. These countries were selected to represent high- and middle-income groups of countries with differing levels of absolute affluence. In 2011, their gross national income per capita ranged from $\$ 3120$ (Ukraine) to $\$ 88,890$ (Norway) US dollars (World Bank, 2012). We excluded individual cases with missing data on geocodes (region or school) or key variables (i.e., gender, age, family affluence and psychosomatic symptoms) and excluded schools with fewer than 10 student observations given our focus on relative differences within schools. These exclusion criteria reduced the sample by $7.7 \%$ - to 48,523 students in 2166 schools, in 141 regions. The number of regions per country ranged from 2 (Norway) to 36 (Austria), number of schools ranged from 105 (Poland) to 434 (Canada) and number of students ranged from 3740 (Belgium-Flanders) to 14,394 (Canada). The sample was $48.97 \%$ male, $51.03 \%$ female and ranged in age from 10.50 to 16.50 years $(M=13.61, \mathrm{SD}=1.63)$. 
Table 1

Family affluence and psychosomatic symptoms among adolescents in eight countries.

\begin{tabular}{|c|c|c|c|c|c|c|c|c|c|}
\hline \multirow[t]{2}{*}{ Country } & \multicolumn{3}{|l|}{$n$} & \multicolumn{3}{|c|}{ Absolute affluence } & \multicolumn{3}{|c|}{ Symptoms } \\
\hline & Students & Schools & Regions & Mean & SD & Skew & Mean & SD & Skew \\
\hline Austria & 4752 & 346 & 36 & 6.04 & 1.78 & -.28 & 33.45 & 13.09 & .04 \\
\hline Belgium & 3740 & 138 & 12 & 6.32 & 1.72 & -.37 & 34.98 & 11.97 & -.26 \\
\hline Canada & 14,394 & 434 & 11 & 6.19 & 1.76 & -.39 & 38.97 & 11.84 & -.35 \\
\hline Norway & 4210 & 177 & 2 & 7.23 & 1.50 & -.91 & 38.20 & 11.31 & -.30 \\
\hline Poland & 4101 & 105 & 17 & 5.34 & 2.03 & -.17 & 39.44 & 12.62 & -.32 \\
\hline Turkey & 5391 & 199 & 4 & 3.09 & 2.05 & .39 & 45.35 & 11.99 & -.73 \\
\hline Scotland & 6566 & 273 & 33 & 6.17 & 1.78 & -.61 & 37.29 & 12.46 & -.41 \\
\hline Ukraine & 5569 & 517 & 26 & 4.25 & 1.92 & -.11 & 41.23 & 11.50 & -.61 \\
\hline Total & 48,523 & 2189 & 141 & 5.64 & 2.15 & -.46 & 38.84 & 12.46 & .25 \\
\hline
\end{tabular}

Note: $\mathrm{SD}=$ Standard deviation

\section{Measures}

\section{Family affluence}

All affluence measures were based on data collected using the HBSC Family Affluence Scale (FAS), a four-item index of material assets or common indicators of wealth (Currie, Elton, Todd, \& Platt, 1997; Wardle, Robb, \& Johnson, 2002). The FAS is composed of four items: "Does your family own a car, van or truck?" (No $=0$, Yes, one $=1$, Yes, two or more $=2$ ); "During the past 12 months, how many times did you travel away on holiday with your family?" (Not at all $=0$, Once $=1$, Twice $=2$, More than twice $=3$ ); How many computers does your family own (None $=0$, One $=1$, Two $=2$, More than two $=3$ ); "Do you have your own bedroom for yourself?" (No $=0$, Yes $=1$ ). The validity of the FAS has been tested alongside longer measures of socioeconomic status that collect data on parental education or income and was found to have better criterion validity and to be less affected by nonresponse bias (Boyce, Torsheim, Currie, \& Zambon, 2006; Torsheim et al., 2004).

Consistent with previous applications of the FAS, absolute affluence was measured by a sum of its items, ranging from 0 (lowest affluence) to 9 (highest affluence; Boyce et al., 2006; Currie et al., 2012). In our analyses, absolute affluence scores were centred around the grand mean of the total sample.

We calculated relative deprivation of each individual within schools and within regions using the Yitzhaki Index (Yitzhaki, 1979). For an individual adolescent $i$ with affluence score of $y_{i}$ who is a member of a reference group of $N$ individuals, relative deprivation $(\mathrm{RD})$ is:

$\mathrm{RD}_{i}=\frac{1}{N} \sum_{j}\left(y_{j}-y_{i}\right), \forall\left(y_{j}>y_{i}\right)$

where the amount of deprivation is operationalized as the average difference in affluence between the individual $i$ and other members of the group who have greater affluence. As such, the Yitzhaki is an "upward looking" index of deprivation. We calculated two estimates of RD for each individual using schools and regions as reference groups.

We also calculated rank affluence of each individual within their schools and regions, thus ignoring distances in affluence between individuals. Rank affluence was calculated within 141 regions and 2189 schools by first calculating the percentile rank in absolute affluence for each student $(i)$ within each group $(n)$, or $((i-.5) / n)$, and then normalising their distribution using an inverse normal function.

\section{Psychosomatic symptoms}

An eight-item psychosomatic symptom checklist measured three psychological symptoms: irritability or bad temper, feeling low, and feeling nervous, and five somatic symptoms, sleeping difficulty, headache, stomach ache, back ache and feeling dizzy (Torsheim \& Wold, 2001). Respondents reported the frequency of each symptom during the previous six months $(0=$ Rarely or never, 1 = Every month, 2 = Every week, 3 = More than once a week, 4 = Every day). The validity of this psychosomatic symptom checklist was supported by cross-national studies and qualitative interviews with adolescents (Haugland \& Wold, 2001; Torsheim \& Wold, 2001). Ravens-Sieberer et al. (2008) carried out a Rasch measurement analysis of differential item functioning (DIF) in this measure and found the scale functioned equally well in $35 \mathrm{HBSC}$ countries. However, to maximise the validity of the scale in our study, we applied Ravens-Sieberer et al.'s (2008) scoring algorithm that removed one item (sleeping difficulty) and recalibrated the scores to control for country-related DIF.

\section{Data analysis}

Calculations of comparative and rank affluence scores and descriptive statistics were compiled used the svy commands in Stata 12.1 (StataCorp Inc., College Station, TX), which adjusted standard errors for country differences and sampling design effects of school cluster. Given the nested structure of the data, we tested associations between affluence and symptoms by fitting threelevel, random effects linear regression models to the data, with students $(i)$ clustered within schools $(j)$ and within countries $(k)$ :

$y_{i j k}=\beta_{0 i j k}+\beta_{1} x_{i j k}+\beta_{2} x_{i j k}+\beta_{3} x_{i j k}$
$\beta_{0 i j k}=\beta_{0}+\nu_{0 k}+\mu_{0 j k}+e_{0 i j k}$

where psychosomatic symptoms $\left(y_{i j k}\right)$ were predicted by a constant $\left(\beta_{0 i j k}\right)$ that included random effects at the country level $\left(v_{0 k}\right)$ and school level $\left(\mu_{0 j k}\right)$ and by fixed effects of individual-level characteristics: female gender $\left(\beta_{1} x_{i j k}\right)$, age in years $\left(\beta_{2} x_{i j k}\right)$ and family affluence $\left(\beta_{3} x_{i j k}\right)$. Random effects at different levels of variance were assumed to be uncorrelated. The fit of non-nested models to the data were compared using Akaike's Information Criterion (AIC), which is a measure of model deviance $(d)$ adjusted for the number of parameters $(q)$ in the model (AIC $=d+2 q$ ), and the more conservative Bayesian information criterion (BIC), which also corrects for differences in the number of observations $(n)$ in the model (Burnham \& Anderson, 2002; BIC $=d+\log (n)^{*} q$ ). Nested models were compared using model deviance and likelihood ratio (LR) tests. Model fit was evaluated using the xtmixed command in Stata 12.1. Where interactions were found between affluent terms, we calculated the simple slopes of RD or rank affluence at high and low levels of absolute affluence (mean $+/-2 \mathrm{SD}$ ). Variance inflation factors (VIF) were used to test for multicollinearity, or the lack of independence between independent variables in a model. VIF values larger than 10 suggests that regression results may be biased due to high degree of multicollinearity (Chatterjee \& Price, 1991). 
Table 2

Descriptive statistics and intercorrelations on family affluence and psychosomatic symptoms in adolescents $(n=48,523)$.

\begin{tabular}{|c|c|c|c|c|c|c|c|c|c|}
\hline & \multirow[t]{2}{*}{ Mean } & \multirow[t]{2}{*}{ SD } & \multirow[t]{2}{*}{ Range } & \multicolumn{6}{|c|}{ Correlations } \\
\hline & & & & 1. & 2. & 3. & 4. & 5. & 6. \\
\hline $\begin{array}{l}\text { 1. Absolute } \\
\text { affluence }\end{array}$ & 5.64 & 2.15 & $.00-9.00$ & - & & & & & \\
\hline $\begin{array}{l}\text { 2. Relative } \\
\text { deprivation } \\
\text { (schools) }\end{array}$ & .94 & 1.01 & $.00-7.20$ & -.76 & - & & & & \\
\hline $\begin{array}{l}\text { 3. Relative } \\
\text { deprivation } \\
\text { (regions) }\end{array}$ & 1.00 & 1.02 & $.00-7.21$ & -.82 & .94 & - & & & \\
\hline $\begin{array}{l}\text { 4. Rank affluence } \\
\text { (schools) }\end{array}$ & .42 & .28 & $.00-1.00$ & .73 & -.81 & -.79 & - & & \\
\hline $\begin{array}{l}\text { 5. Rank affluence } \\
\text { (regions) }\end{array}$ & .42 & .28 & $.00-1.00$ & .79 & -.81 & -.86 & .92 & - & \\
\hline $\begin{array}{l}\text { 6. Psychosomatic } \\
\text { symptoms }\end{array}$ & 38.84 & 12.46 & $13.59-86.16$ & -.14 & .05 & -.03 & -.03 & -.04 & - \\
\hline
\end{tabular}

Note: $\mathrm{SD}=$ Standard deviation. All correlations are significant at $p<.01$.

\section{Results}

Descriptive statistics on the main variables in this study are shown in Table 1 . We inspected the distribution of the data on absolute affluence given the large differences in per capita incomes between the eight countries. As shown in Table 1, there was moderate positive skewness in the absolute affluence variable in Turkey and moderate negative skewness in absolute affluence in the remaining seven countries. Some positive skewness was also evident in psychosomatic symptoms, which is typical of symptom data on community samples. Overall, the distribution of data on family affluence and symptoms did not violate the statistical assumptions of our models. Table 2 shows additional descriptive statistics on absolute affluence, $\mathrm{RD}$, rank affluence and symptoms and intercorrelations among these variables.

We then tested a series of multilevel linear regression models of psychosomatic symptoms. Table 3 shows the results of four nonnested models that differed according to which affluence variable was entered: absolute affluence (Model 1), RD in schools (Model 2), $\mathrm{RD}$ in regions (Model 3), rank affluence in schools (Model 4) and rank affluence in regions (Model 5). The low intraclass correlations (ICCs) in these models indicated some similarities within schools and countries but, overall, most of the variance in symptoms occurred between individuals. Together, gender, age and affluence accounted for $16 \%$ of the variance in symptoms. Each model allowed for random variances at the student, school and country levels and fixed effects of age, gender and affluence.

With the other differences in symptoms held constant, females scored higher than males $(b=4.4)$ and each additional year of age corresponded with 1.1-point increase in symptoms. A 1-point increase in absolute affluence corresponded to a difference of -.27 in symptoms. Across the full range of RD was about a half-point difference in symptoms. Between the top and bottom rank position in schools was a difference of .43 in symptoms and between the top and bottom rank position in regions was a half-point difference in symptoms. All five regression models of symptoms fit the data about equally well, however the model containing rank affluence in regions showed the lowest model deviance, AIC and BIC values and therefore best fit to the data. The model containing absolute affluence showed the worst model fit to the data.

Next, we tested whether each relative affluence variable related to psychosomatic symptoms after differences in absolute affluence were controlled (Table 4). RD (in schools) and RD (in regions) both showed unique associations with symptoms. The addition of RD variables to the model resulted in significantly better model fit and the associations between absolute affluence and symptoms became no longer significant. Rank affluence in schools did not uniquely influence symptoms. However, rank affluence in regions negatively related to symptoms with differences in absolute affluence held constant (Table 4). The association between absolute affluence and symptoms was no longer significant after rank affluence (in regions) was included in the model. Again, differences in the fit of these models of relative affluence to the data were marginal.

An additional set of analyses found that absolute and relative affluence interacted in their relations to symptoms (Table 5). These interactions were small but all statistically significant. The simple slopes of these interactions are shown in Fig. 1 and indicate that RD and rank affluence variables related more closely to symptoms at lower levels of absolute affluence. The variance inflation factors (VIFs) in all these models were low (below 4.1), indicating that these results were not biased by multicollinearity between independent variables.

\section{Discussion}

This study explored socioeconomic differences in psychosomatic symptoms in a large, international sample of adolescents. The

Table 3

Multilevel regression analyses of psychosomatic symptoms predicted by absolute affluence, relative deprivation or rank affluence $(n=48,523)$.

\begin{tabular}{|c|c|c|c|c|c|c|c|c|c|c|}
\hline & \multicolumn{2}{|l|}{ Model 1} & \multicolumn{2}{|l|}{ Model 2} & \multicolumn{2}{|l|}{ Model 3} & \multicolumn{2}{|l|}{ Model 4} & \multicolumn{2}{|l|}{ Model 5} \\
\hline & $b(\mathrm{SE})$ & $Z$ & $b(\mathrm{SE})$ & $Z$ & $b(\mathrm{SE})$ & $Z$ & $b(\mathrm{SE})$ & $Z$ & $b(\mathrm{SE})$ & $Z$ \\
\hline \multicolumn{11}{|l|}{ Fixed effects: } \\
\hline Intercept $\left(\beta_{0 i j k}\right)$ & $17.03(1.20)$ & & $17.04(1.28)$ & & $16.57(1.27)$ & & $16.90(1.28)$ & & $16.90(1.28)$ & \\
\hline Gender (female) & $4.39(.11)$ & $41.19^{*}$ & $4.39(.11)$ & $41.20^{*}$ & $4.40(.11)$ & $41.21^{*}$ & $4.40(.11)$ & $41.22^{*}$ & $4.39(.11)$ & $41.18^{*}$ \\
\hline Age & $1.09(.04)$ & $27.42^{*}$ & $1.09(.04)$ & $27.37^{*}$ & $1.09(.11)$ & $27.39 *$ & $1.10(.04)$ & $27.41^{*}$ & $1.09(.04)$ & $27.43^{*}$ \\
\hline Absolute affluence & $-.27(.03)$ & $-8.95^{*}$ & & & & & & & & \\
\hline Relative deprivation - schools & & & $.49(.05)$ & $-9.80^{*}$ & & & & & & \\
\hline Relative deprivation - regions & & & & & $.49(.05)$ & $-9.82^{*}$ & & & & \\
\hline Rank affluence - schools & & & & & & & $-.43(.06)$ & $-7.71^{*}$ & & \\
\hline Rank affluence - regions & & & & & & & & & $-.50(.05)$ & $-10.01^{*}$ \\
\hline \multicolumn{11}{|l|}{ Variance components: } \\
\hline$\sigma_{e}^{2}$ (student) & $133.15(.87)$ & & $133.10(.87)$ & & $133.13(.87)$ & & $133.18(.87)$ & & $133.15(.87)$ & \\
\hline$\sigma_{\mu 0}^{2}($ school $)$ & $4.23(.35)$ & & $4.29(.35)$ & & $4.22(.35)$ & & $4.28(.35)$ & & $4.20(.35)$ & \\
\hline$\sigma_{\nu 0}^{2}($ country $)$ & $8.95(4.50)$ & & $10.39(5.22)$ & & $10.32(5.19)$ & & $10.46(5.26)$ & & $10.42(5.23)$ & \\
\hline \multicolumn{11}{|l|}{ Goodness-of-fit: } \\
\hline Deviance & $376,167.6$ & & $376,161.2$ & & $376,160.6$ & & $376,188.0$ & & $376,160.4$ & \\
\hline AIC & $376,181.6$ & & $376,175.3$ & & $376,174.6$ & & $376,202.1$ & & $376,175.5$ & \\
\hline BIC & $376,243.2$ & & $376,236.8$ & & $376,236.2$ & & $376,263.6$ & & $376,236.0$ & \\
\hline
\end{tabular}

${ }^{*} p<.01$.

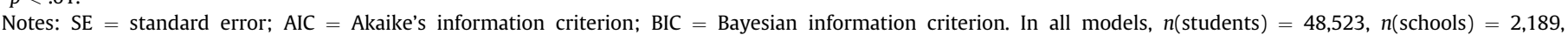
$n$ (countries) $=8, R^{2}=.16$, Intraclass correlations $=.06-.07$ (countries), .09-.10 (schools). 
Table 4

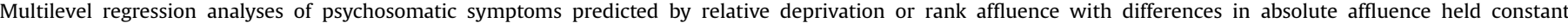
$(n=48,523)$.

\begin{tabular}{|c|c|c|c|c|c|c|c|c|}
\hline & \multicolumn{2}{|l|}{ Model 1} & \multicolumn{2}{|l|}{ Model 2} & \multicolumn{2}{|l|}{ Model 3} & \multicolumn{2}{|l|}{ Model 4} \\
\hline & $b(\mathrm{SE})$ & $Z$ & $b(\mathrm{SE})$ & $Z$ & $b(\mathrm{SE})$ & $Z$ & $b(\mathrm{SE})$ & $Z$ \\
\hline \multicolumn{9}{|l|}{ Fixed effects: } \\
\hline Intercept $\left(\beta_{0 i j k}\right)$ & $17.04(1.25)$ & & $17.05(1.26)$ & & $17.02(1.18)$ & & $17.06(1.29)$ & \\
\hline Gender (female) & $4.39(.11)$ & $41.19^{*}$ & $4.40(.11)$ & $41.20^{*}$ & $4.39(.11)$ & $41.19^{*}$ & $4.39(.11)$ & $41.18^{*}$ \\
\hline Age & $1.09(.04)$ & $27.39^{*}$ & $1.09(.04)$ & $27.40^{*}$ & $1.09(.04)$ & $27.41^{*}$ & $1.09(.04)$ & $27.43^{*}$ \\
\hline Absolute affluence & $-.09(.07)$ & -1.35 & $-.05(.08)$ & -.63 & $-.35(.07)$ & $-4.69 *$ & $.06(.12)$ & .46 \\
\hline Relative deprivation - schools & $.34(.12)$ & $2.87^{*}$ & & & & & & \\
\hline Relative deprivation - regions & & & $.41(.15)$ & $2.73^{*}$ & & & & \\
\hline Rank affluence - schools & & & & & $-.16(.14)$ & -1.17 & & \\
\hline Rank affluence - regions & & & & & & & $-.60(.22)$ & $-2.74^{*}$ \\
\hline \multicolumn{9}{|l|}{ Variance components: } \\
\hline$\sigma_{e}^{2}$ (student) & $133.11(.87)$ & & $133.13(.87)$ & & $133.15(.87)$ & & $133.15(.87)$ & \\
\hline$\sigma_{\mu 0}^{2}($ school $)$ & $4.26(.35)$ & & $4.22(.35)$ & & $4.23(.35)$ & & $4.20(.35)$ & \\
\hline$\sigma_{\nu 0}^{2}$ (country) & $9.86(4.97)$ & & $10.03(5.06)$ & & $8.54(4.31)$ & & $10.75(5.43)$ & \\
\hline \multicolumn{9}{|l|}{ Goodness-of-fit: } \\
\hline Deviance & $376,159.4$ & & $376,160.2$ & & $376,166.2$ & & $376,164.0$ & \\
\hline LR test vs. Model 1 (Table 3) & $8.19^{*}$ & & $7.41^{*}$ & & 1.36 & & $7.39^{*}$ & \\
\hline
\end{tabular}

${ }^{*} p<.01$.

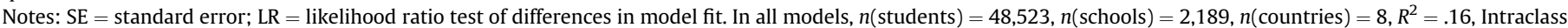

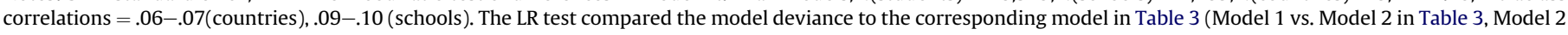
vs. Model 3 in Table 3, etc.).

goal of the study was twofold. First, we wanted to determine whether absolute affluence and relative affluence differed in the strength of their relations to symptoms. Second, as a direct test of a psychosocial pathway between SES and adolescent health, we explored whether RD or rank affluence related to symptoms after differences in absolute affluence were held constant. Four formulations of relative affluence were tested so we could compare RD and rank in two reference groups - schools and regions.

The results show marginal support for the first hypothesis. Although psychosomatic symptoms related to all five measures of affluence, rank affluence within regions constituted the best predictive model and absolute affluence constituted the worst. Overall, these results were consistent with a psychosocial interpretation of SES differences in health and contextual effects of income inequality on health, but it should be noted that absolute affluence - a material path - related to symptoms as well.
Stronger support was found for our second hypothesis. Three out of the four measures of relative affluence - RD in schools, RD in regions and rank affluence in regions - predicted psychosomatic symptoms after differences in absolute affluence were statistically fixed at zero. Only rank affluence in schools failed to uniquely predict symptoms. This inconsistency in the results could have been due to the stratification of students within schools, which might have been concentrated towards the bottom of the affluence hierarchy and not equally distributed across rank. Still, as Subramanyam et al. (2009) and Boyce et al. (2010) found in studies of RD and income rank in adults, we found that adolescents' symptoms were uniquely influenced by relative differences in affluence among their peers.

Finally, absolute and relative affluence interacted in ways that were not apparent in their bivariate correlations. Each interaction suggests that relative differences in affluence relates more closely to health at lower levels of absolute affluence. We hypothesised that RD and rank

Table 5

Multilevel regression analyses of psychosomatic symptoms predicted by interactions of absolute, relative and rank family affluence $(n=48,523)$.

\begin{tabular}{|c|c|c|c|c|c|c|c|c|}
\hline & \multicolumn{2}{|l|}{ Model 1} & \multicolumn{2}{|l|}{ Model 2} & \multicolumn{2}{|l|}{ Model 3} & \multicolumn{2}{|l|}{ Model 4} \\
\hline & $b(\mathrm{SE})$ & $Z$ & $b(\mathrm{SE})$ & $Z$ & $b(\mathrm{SE})$ & $Z$ & $b(\mathrm{SE})$ & $Z$ \\
\hline \multicolumn{9}{|l|}{ Fixed effects: } \\
\hline Intercept $\left(\beta_{0 i j k}\right)$ & $16.93(1.22)$ & & $16.92(1.21)$ & & $16.92(1.18)$ & & $16.94(1.26)$ & \\
\hline Gender (female) & $4.40(.11)$ & $41.20^{* *}$ & $4.40(.11)$ & $41.22^{* *}$ & $4.39(.11)$ & $41.19^{* *}$ & $4.40(.11)$ & $41.21^{* *}$ \\
\hline Age & $1.09(.04)$ & $27.37^{* *}$ & $1.09(.04)$ & $27.40^{* *}$ & $1.09(.04)$ & $27.42^{* *}$ & $1.09(.04)$ & $27.45^{*}$ \\
\hline Absolute affluence & $-.20(.08)$ & $-2.49^{*}$ & $-.21(.11)$ & $-1.97^{*}$ & $-.32(.07)$ & $-.4 .36^{* *}$ & $-.04(.12)$ & -.34 \\
\hline Relative deprivation - schools & $.05(.17)$ & .30 & & & & & & \\
\hline Relative deprivation - regions & & & $.01(.23)$ & .04 & & & & \\
\hline Rank affluence - schools & & & & & $-.14(.14)$ & 1.01 & & \\
\hline Rank affluence - regions & & & & & & & $-.38(.23)$ & -1.66 \\
\hline Absolute X RD - schools & $-.07(.03)$ & $-2.53^{*}$ & & & & & & \\
\hline Absolute X RD - regions & & & $-.07(.03)$ & $-2.31^{*}$ & & & & \\
\hline Absolute X Rank - schools & & & & & $.07(.02)$ & $3.10^{* *}$ & & \\
\hline Absolute X Rank - regions & & & & & & & $.06(.02)$ & $3.07^{* *}$ \\
\hline \multicolumn{9}{|l|}{ Variance components: } \\
\hline$\sigma_{e}^{2}$ (student) & $133.11(.87)$ & & $133.13(.87)$ & & $133.15(.87)$ & & $133.15(.87)$ & \\
\hline$\sigma_{\mu 0}^{2}($ school $)$ & $4.24(.35)$ & & $4.22(.35)$ & & $4.20(.35)$ & & $4.20(.35)$ & \\
\hline$\sigma_{\nu 0}^{2}$ (country) & $9.31(4.70)$ & & $9.16(4.64)$ & & $10.75(5.43)$ & & $10.75(4.21)$ & \\
\hline \multicolumn{9}{|l|}{ Goodness-of-fit: } \\
\hline Deviance & $376,153.0$ & & 376,155 & & 376,164 & & $376,150.8$ & \\
\hline LR test (c.f. Table 4) & $6.40^{*}$ vs. Model 2 & & $5.29^{*}$ vs. Model 3 & & $9.64^{*}$ vs. Model 4 & & $9.43^{* *}$ vs. Model 5 & \\
\hline
\end{tabular}

${ }^{*} p<.05 .{ }^{* *} p<.01$.

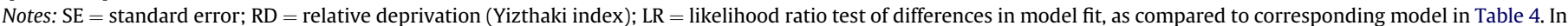
all models, $n$ (students $)=48,523, n$ (schools $)=2189, n$ (countries) $=8, R^{2}=.16$, Intraclass correlations $=.06-.07$ (countries), $.09-.10$ (schools). 

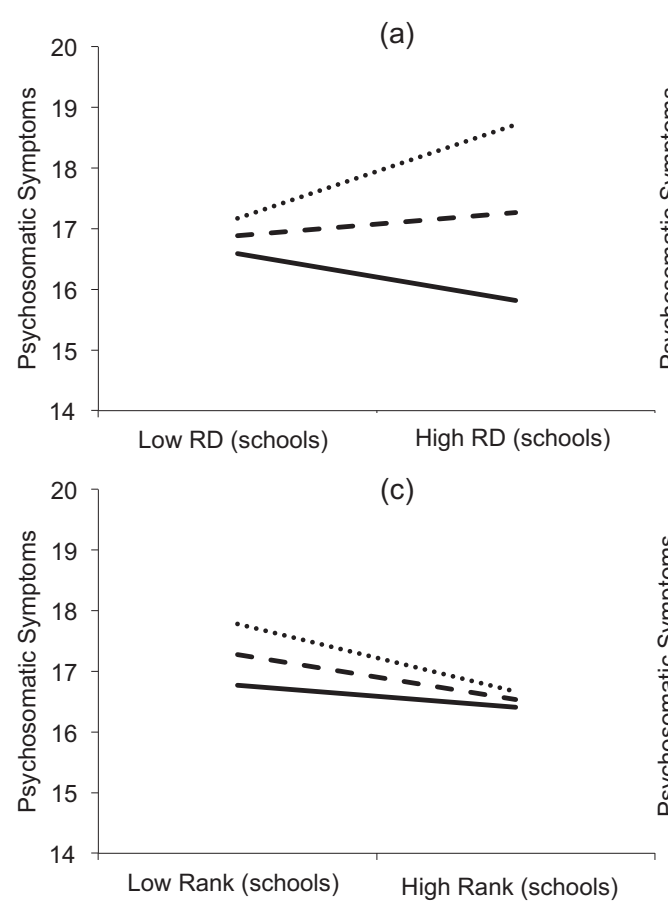

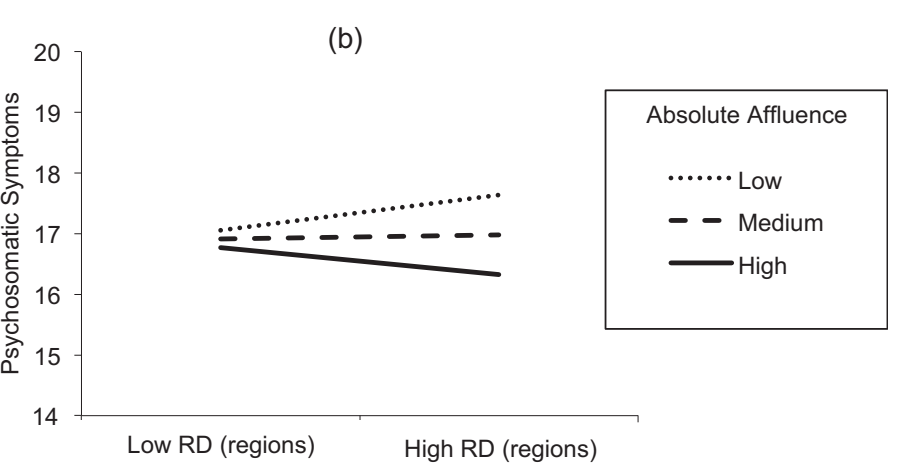

(d)

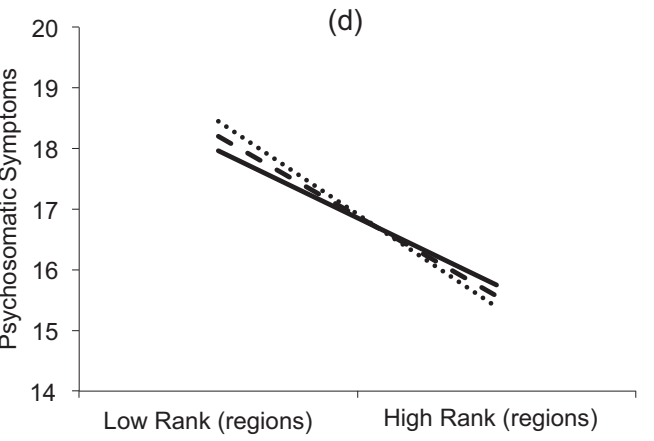

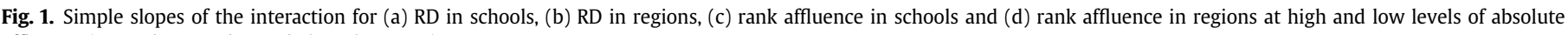
affluence (1 SD above and $1 \mathrm{SD}$ below the mean).

would relate to health equally at all levels of absolute affluence, but found instead that relative deprivation and status matter more at the bottom and have diminishing returns at higher levels of absolute affluence. An alternative interpretation of these findings is that the relations between relative affluence and symptoms were attenuated by a 'floor effect' caused by a narrower range of symptom scores among the most affluent (and healthiest) adolescents.

Taken together, these results indicate that family material affluence is a robust predictor of psychosomatic symptoms in adolescents. Regardless of whether affluence was measured in purely absolute terms (i.e., as an index of material assets listed on the FAS) or as relative differences within groups, family affluence negatively related to symptoms in adolescents. The findings dovetail with the large body of evidence on SES differences in health and well-being (Adler \& Snibbe, 2003; Chen \& Paterson, 2006; Elgar et al., 2010; Galobardes, Smith, \& Lynch, 2006). Unique to this study was the demonstration that relative affluence is at least as strong a predictor of adolescent symptoms as absolute affluence, thus supporting the psychosocial hypothesis about mechanisms that underlie socioeconomic inequalities in adolescent health. The findings are consistent with those on RD, income rank and adult health (Adjaye-Gbewonyo \& Kawachi, 2012; Boyce et al., 2010) and extend these constructs to adolescent health. We conclude that socioeconomic status impacts adolescent health through the psychosocial impact of relative deprivation and social rank, in addition to an uneven distribution of material goods and services that support health (Chen \& Paterson, 2006; Currie et al., 2008).

Our findings also highlight a fundamental distinction between absolute and relative affluence and its implications for how SES is operationalized in research - not only in the HBSC study but in other international studies as well. Given the type of data measured by the FAS (i.e., cars, computers, vacations and bedrooms), it could be argued that relative differences in FAS scores are conceptually closer to the construct of SES than a simple summation of its items. Differentiating absolute and relative affluence is especially important in research carried out on samples representing different socioeconomic contexts. The principle of RD explains why a score of 4 on the FAS can simultaneously indicate high SES in a poor country and low SES in a rich country. The summation of material assets, as easily done with the FAS, disregards context and therefore does not measure relative socioeconomic position. Yet, in numerous studies that are grounded in theory and evidence about socioeconomic differences in health, assessments of absolute and relative affluence are used interchangeably to measure SES. We show that available data on absolute affluence can be transformed to $\mathrm{RD}$ or rank to provide more precise estimates of SES.

Indices of material assets have other limitations that are more difficult to overcome. In the HBSC study, for example, some items in the FAS show differential item functioning across gender and rural/ urban groups, countries or survey cycles, which makes it difficult to interpret differences in its total score (Schnohr et al., 2008). As well, past research has not agreed on whether the types of assets measured by the FAS reflect an underlying construct of affluence or if these assets themselves constitute affluence. This debate focuses on whether the FAS is a reflective or formative index of material affluence (Currie et al., 2008; Schnohr et al., 2008).

In summary, this examination of absolute and relative socioeconomic conditions in relation to psychosomatic symptoms contributes to the research literature on social inequalities in health. An obvious limitation was its cross-sectional design, which precluded strong conclusions about the direction of effects on affluence and health. Longitudinal research would provide clearer evidence of how socioeconomic circumstances early in life shape health inequalities in adolescence. Also, multiple assessments of socioeconomic conditions using standard measures of parental occupation or household income might have provided more precise estimates of SES than material assets. Continued development of such measures of socioeconomic differences in youth has implications to health policy. Such research has the potential to provide a better understanding of the origins of socioeconomic differences in adult health and the material and psychosocial mechanisms that support them (Starfield, Riley, Witt, \& Robertson, 2002). 


\section{Acknowledgements}

The Health Behaviour in School-aged Children (HBSC) study is a World Health Organization collaborative study and funded by each of its member countries. The HBSC International Coordinating Centre is located at St. Andrew's University (Scotland) and databank is managed at the University of Bergen (Norway). A list of the participating researchers can be found online at www.hbsc.org. This research was also funded by grants from the Social Sciences and Humanities Research Council of Canada and Canada Research Chairs Programme awarded to the first author. The authors also thank Malavika Subramanyam and S.V. Subramanian for the assistance with the analysis and two blind reviewers for their helpful suggestions.

\section{References}

Åberg Yngwe, M., \& Östberg, V. (2013). The family's economic resources and adolescents' health complaints-do adolescents' own economic resources matter? European Journal of Public Health, 23(1), 24-29.

Adjaye-Gbewonyo, K., \& Kawachi, I. (2012). Use of the Yitzhaki index as a test of relative deprivation for health outcomes: a review of recent literature. Social Science \& Medicine, 75(1), 129-137.

Adler, N. E., \& Snibbe, A. C. (2003). The role of psychosocial processes in explaining the gradient between socioeconomic status and health. Current Directions in Psychological Science, 12(4), 119-123.

Boyce, C. J., Brown, G. D., \& Moore, S. C. (2010). Money and happiness: rank of income, not income, affects life satisfaction. Psychological Science, 21(4), 471-475.

Boyce, W., Torsheim, T., Currie, C., \& Zambon, A. (2006). The family affluence scale as a measure of national wealth: validation of an adolescent self-report measure. Social Indicators Research, 78(3), 473-487.

Brooks-Gunn, J., Duncan, G. J., \& Maritato, N. (1997). Poor families, poor outcomes: the well being of children and youth. In G. J. Duncan, \& J. Brooks-Gunn (Eds.), Consequences of growing up poor (pp. 1-17). New York: Russel Sage Foundation.

Burnham, K. P., \& Anderson, D. R. (2002). Model selection and multimodel inference: A practical information-theoretic approach (2nd ed.). New York: Springer.

Chatterjee, S., \& Price, B. (1991). Regression analysis by example (2nd ed.). New York: Wiley.

Chen, E., Matthews, K. A., \& Boyce, W. T. (2002). Socioeconomic differences in children's health: how and why do these relationships change with age? Psychological Bulletin, 128(2), 295-329.

Chen, E., \& Paterson, L. Q. (2006). Neighborhood, family, and subjective socioeconomic status: how do they relate to adolescent health? Health Psychology, 25(6), 704-714.

Currie, C. E., Elton, R. A., Todd, J., \& Platt, S. (1997). Indicators of socioeconomic status for adolescents: the WHO health behaviour in school-aged children survey. Health Education Research, 12(3), 385-397.

Currie, C., Molcho, M., Boyce, W., Holstein, B., Torsheim, T., \& Richter, M. (2008) Researching health inequalities in adolescents: the development of the health behaviour in school-aged children (HBSC) family affluence scale. Social Science E' Medicine., 66(6), 1429-1436.

Currie, C. Zanotti, C., Morgan, A., Currie D., de Looze, M. Roberts, C et al (2012) Social determinants of health and well-being among young people. Health behaviour in school-aged children (HBSC) study: International report from the 2009/2010 survey. In Health policy for children and adolescents (No. 6). Copenhagen: WHO Regional Office for Europe.

Diener, E., Sandvik, E., Seidlitz, L., \& Diener, M. (1993). The relationship between income and subjective well-being: relative or absolute? Social Indicators Research, 28, 195-223.
Easterlin, R. A. (1995). Will raising the incomes of all increase the happiness of all? Journal of Economic Behavior and Organization, 27(1), 35-48.

Elgar, F. J., Craig, W., Boyce, W., Morgan, A., \& Vella-Zarb, R. (2009). Income inequality and school bullying: multilevel study of adolescents in 37 countries. Journal of Adolescent Health, 45(4), 351-359.

Elgar, F. J., Trites, S. J., \& Boyce, W. (2010). Social capital reduces socio-economic differences in child health: evidence from the Canadian health behaviour in school-aged children study. Canadian Journal of Public Health, 101(Suppl. 3), 23-27.

Galobardes, B., Smith, G. D., \& Lynch, J. W. (2006). Systematic review of the influence of childhood socioeconomic circumstances on risk for cardiovascular disease in adulthood. Annals of Epidemiology, 16(2), 91-104.

Haugland, S., \& Wold, B. (2001). Subjective health complaints in adolescence: reliability and validity of survey methods. Journal of Adolescence, 24(5), $611-624$.

Loughnan, S., Kuppens, P., Allik, J., Balazs, K., de Lemus, S., Dumont, K., et al. (2011) Economic inequality is linked to biased self-perception. Psychological Science, 22(10), 1254-1258.

Mackenbach, J. P. (2012). The persistence of health inequalities in modern welfare states: the explanation of a paradox. Social Science E' Medicine, 75(4), 761-769.

Marmot, M. (2004). Status syndrome: How your social standing directly affects your health and life expectancy. London: Bloomsbury Publishing.

Marmot, M., \& Wilkinson, R. G. (2001). Psychosocial and material pathways in the relation between income and health: a response to Lynch et al. British Medical Journal, 322(7296), 1233-1236.

Pickett, K. E., \& Wilkinson, R. G. (2007). Child wellbeing and income inequality in rich societies: ecological cross sectional study. British Medical Journal, 335(7629), 1080

Ravens-Sieberer, U., Erhart, M., Torsheim, T., Hetland, J., Freeman, J., Danielson, M., et al. (2008). An international scoring system for self-reported health complaints in adolescents. European Journal of Public Health, 18(3), 294-299.

Reagan, P. B., Salsberry, P. J., \& Randall, O. J. (2007). Does the measure of economic disadvantage matter? Exploring the effect of individual and relative deprivation on intrauterine growth restriction. Social Science E' Medicine, 64(10), 2016-2029.

Schnohr, C., Kreiner, S., Due, P., Currie, C., Boyce, W., \& Diderichsen, F. (2008). Differential item functioning of a family affluence scale: validation study on data from HBSC 2001/02. Social Indicators Research, 89(1), 79-95.

Starfield, B., Riley, A.,W., Witt, W. P., \& Robertson, J. (2002). Social class gradients in health during adolescence. Journal of Epidemiology and Community Health, 56(5), 354-361.

Subramanyam, M., Kawachi, I., Berkman, L., \& Subramanian, S. V. (2009). Relative deprivation in income and self-rated health in the United States. Social Science E Medicine, 69(3), 327-334.

Torsheim, T., Currie, C., Boyce, W., Kalnins, I., Overpeck, M., \& Haugland, S. (2004) Material deprivation and self-rated health: a multilevel study of adolescents from 22 European and North American countries. Social Science \& Medicine, 59(1), 1-12.

Torsheim, T. \& Wold, B. (2001). School-related stress, support, and subjective health complaints among early adolescents: a multilevel approach. Journal of Adolescence, 24(6), 701-713.

Wardle, J., Robb, K., \& Johnson, F. (2002). Assessing socioeconomic status in adolescents: the validity of a home affluence scale. Journal of Epidemiology and Community Health, 56(8), 595-599.

West, P., \& Sweeting, H. (2004). Evidence on equalisation in health in youth from the west of Scotland. Social Science E Medicine, 59(1), 13-27.

Wilkinson, R. G., \& Pickett, K. (2009). The spirit level: Why more equal societies almost always do better. London: Allen Lane.

Wood, A. M., Boyce, C. J., Moore, S. C., \& Brown, G. D. (2012). An evolutionary based social rank explanation of why low income predicts mental distress: a 17-year cohort study of 30,000 people. Journal of Affective Disorders, 136(3), 882-888.

World Bank. (2012). World development indicators database. Accessed 17.09.12 http://databank.worldbank.org.

Yitzhaki, S. (1979). Relative deprivation and the Gini coefficient. The Quarterly Journal of Economics, 93(2), 321-324. 